\title{
A multidisciplinary hospital-based antimicrobial use program: Impact on hospital pharmacy expenditures and drug use
}

\author{
Suzette Salama BPharm PhD, Coleman Rotstein mD fRCPC, LIONEL MANDELL MD FRCPC
}

S SALAMA, C ROTSTEIN, L MANDELL. A multidisciplinary hospital-based antimicrobial use program: Impact on hospital pharmacy expenditures and drug use. Can J Infect Dis 1996;7(2):104-109.

\begin{abstract}
The authors' hospital embarked on a three-component, multidisciplinary, hospital-based antimicrobial use program to cut costs and reduce inappropriate antimicrobial use. Initially, antimicrobial use patterns and costs were monitored for 12 months. For the next two years, an antimicrobial use program was implemented consisting of three strategies: automatic therapeutic interchanges; antimicrobial restriction policies; and parenteral to oral conversion. The program resulted in a reduction in the antimicrobial portion of the total pharmacy drug budget from $41.6 \%$ to $28.2 \%$. Simultaneously, the average cost per dose per patient day dropped from $\$ 11.88$ in 1991 to $\$ 10.16$ in 1994 . Overall, mean monthly acquisition cost savings rose from $\$ 6,810$ in 1992 to $\$ 27,590$ in 1994 . This study demonstrates that a multidisciplinary antimicrobial use program in a Canadian hospital can effect dramatic cost savings and serve as a quality assurance activity of physician antimicrobial prescribing behaviour.
\end{abstract}

Key Words: Antibiotic use program, Hospital expenditure

Programme hospitalier pluridisciplinaire d'antibiothérapie : impact sur les dépenses de la pharmacie de l'hôpital et sur l'emploi des médicaments

RÉSUMÉ : L'établissement des auteurs a amorcé un programme hospitalier pluridisciplinaire d'antibiothérapie en trois volets afin de réduire les coûts et de prévenir l'emploi inapproprié des antibiotiques. Au départ, les modes d'utilisation des antibiotiques et les coûts ont été surveillés pendant 12 mois. Pendant les deux années suivantes, un programme d'antibiothérapie comportant trois stratégies a été mis en application : substitution thérapeutique automatique, politique de restriction des antibiotiques et conversion de la voie parentérale à la voie orale. Le programme a entraîné une réduction de la portion antimicrobienne du budget total de la pharmacie en terme de médicaments, soit de 41,6\% à $28,2 \%$. Simultanément, le coût moyen par dose par patient a chuté de 11,88 \$ en 1991 à 10,96 \$ en 1994. De façon globale, les économies en matière de coût mensuel d'acquisition se sont élevées de 6810 \$ en 1992 à 27590 \$ en 1994 . Cette étude démontre qu'un programme d'utilisation pluridisciplinaire des antibiotiques dans un hôpital canadien peut amener des économies considérables en terme de coûts et servir de mesure d'assurance de la qualité lorsqu'il est question des habitudes d'ordonnance des médecins en matière d'antibiothérapie.

Departments of Pharmacy and Medicine, the Henderson General Division, Hamilton Civic Hospitals, and the Division of Infectious Diseases, McMaster University, Hamilton, Ontario

Correspondence and reprints: Dr Coleman Rotstein, McMaster Medical Unit, Henderson General Hospital, 711 Concession Street, Hamilton, Ontario L8V 1C3. Telephone 905-574-3301, fax 905-575-7320, e-mail crotstei@fhs.mcmaster.ca

Received for publication July 11, 1995. Accepted November 15, 1995 
$\mathrm{T}$ he benefits of antimicrobial use for the treatment and prevention of community acquired and nosocomial infections are readily evident. However, emerging antimicrobial resistance (1-3), escalating drug acquisition costs (4), inappropriate antimicrobial usage $(5,6)$ and adverse drug effects $(6)$ have prompted physicians, pharmacists and hospital administrators (7) to develop programs to evaluate antimicrobial use and to promote rational and cost effective use of these drugs. In particular, concerns about antimicrobial resistance (1-3) with the subsequent development of nosocomial infection (8) and cost containment issues (4-6) have accelerated the development of such strategies.

It has been reported that antimicrobial costs constitute $20 \%$ to $50 \%$ of a hospital's total drug budget (9-14). Our institution is a tertiary care university teaching hospital in which antimicrobials accounted for over $40 \%$ of the pharmacy's drug acquisition costs. As a result, this class of drugs was targeted for increased scrutiny during an era of expenditure curtailment.

With the objectives of cutting costs and reducing inappropriate antimicrobial use, our hospital implemented a threecomponent, multidisciplinary hospital-based, antimicrobial use program in August 1992. It was anticipated that this would improve the quality of patient care and decrease drug costs. This report describes the results of our program and its impact on antimicrobial use and expenditures.

\section{MATERIALS AND METHODS}

Baseline antimicrobial use patterns and expenditure data at the hospital were gathered for a 12-month period before the initiation of the antimicrobial use program. Due to the regionalization of medical services in the Hamilton-Wentworth region, the focus of the 465-bed hospital is general medicine and surgery, oncology, obstetrics and gynecology, and orthopedic prosthetic surgery.

During the 12-month period preceding the implementation of the program, three antimicrobial management strategies were put into place. As a first step, the antimicrobial hospital formulary was streamlined by the Pharmacy and Therapeutics Committee. Drugs that duplicated clinical efficacy, possessed higher toxicity profiles, had inferior pharmacokinetic properties or were more expensive were deleted. Next, an automatic three-day stop order was enforced for all antimicrobials, thereby necessitating reassessment of therapy before the drug was reordered. Finally, clinical antimicrobial therapy guidelines for community acquired and nosocomial infections were introduced to hospital medical staff through the use of newsletters, departmental in-services, educational rounds, pocket charts and wall posters. The clinical therapeutic guidelines were developed jointly by the Infectious Diseases service and the hospital pharmacists with subsequent approval by the hospital's Pharmacy and Therapeutics Committee.

Development and implementation of the multidisciplinary antimicrobial use program involved physicians, pharmacists, nurses and administrative personnel. The three strategies of this program, which are described below, were approved by the hospital Medical Staff Advisory Committee and activated in August 1992, following an extensive educational program.
TABLE 1

Therapeutic interchange of antimicrobial agents

\begin{tabular}{lll}
\hline Original drug and dose & & Substituted drug and dose \\
\hline Ampicillin & $\rightarrow$ & Amoxicillin \\
250-500 mg q6h po & & 250-500 mg q8h po \\
Cephalothin 1-2 g q4h IV & $\rightarrow$ & Cefazolin 1-2 g q8h IV \\
Cefamandole 1-2 g q6h IV & $\rightarrow$ & Cefuroxime 0.75 g q8h IV \\
Cefoxitin 1-2 g q6h IV & $\rightarrow$ & Cefotetan 1 g q12h IV \\
Cefotaxime 2 g q8h IV & $\rightarrow$ & Ceftriaxone 1 g q24h IV \\
Cefotaxime 2 g q4h IV & $\rightarrow$ & Ceftriaxone 2 g q12h IV \\
Tobramycin & $\rightarrow$ & Gentamicin \\
1.5 mg/kg q8-24h IV & & 1.5 mg/kg q8-24h IV \\
Clindamycin & $\rightarrow$ & Clindamycin \\
600 mg q6h IV & & 600 mg q8h IV \\
Vancomycin & $\rightarrow$ & Metronidazole \\
125 mg q6h po & & 500 mg q8h po
\end{tabular}

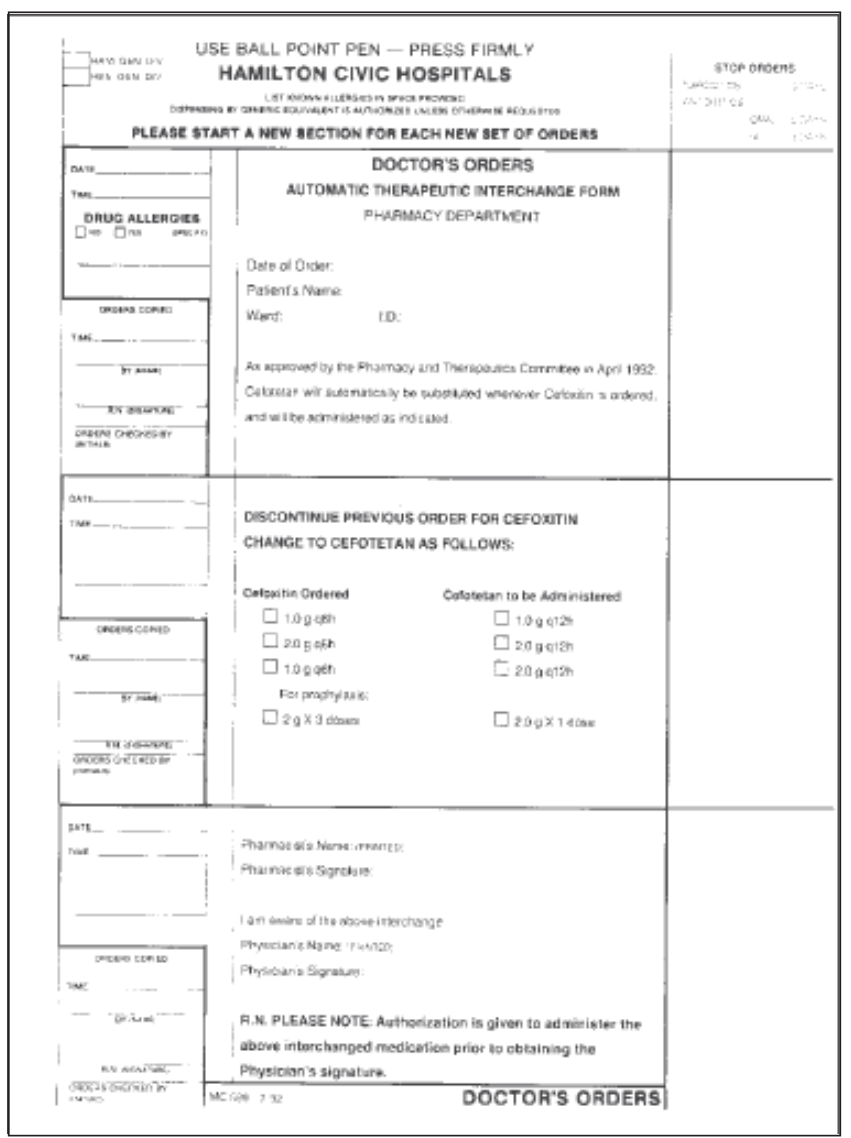

Figure 1) Sample of therapeutic interchange form

Strategy 1 - automatic therapeutic interchanges: Based on the hospital's newly streamlined antimicrobial formulary, nine possible automatic therapeutic substitutions were identified. When a physician ordered one of eight specified antimicrobials, the drug was automatically replaced by a therapeutic equivalent. Interchanges took effect immediately and physicians were notified of the substitution by means of specific in- 


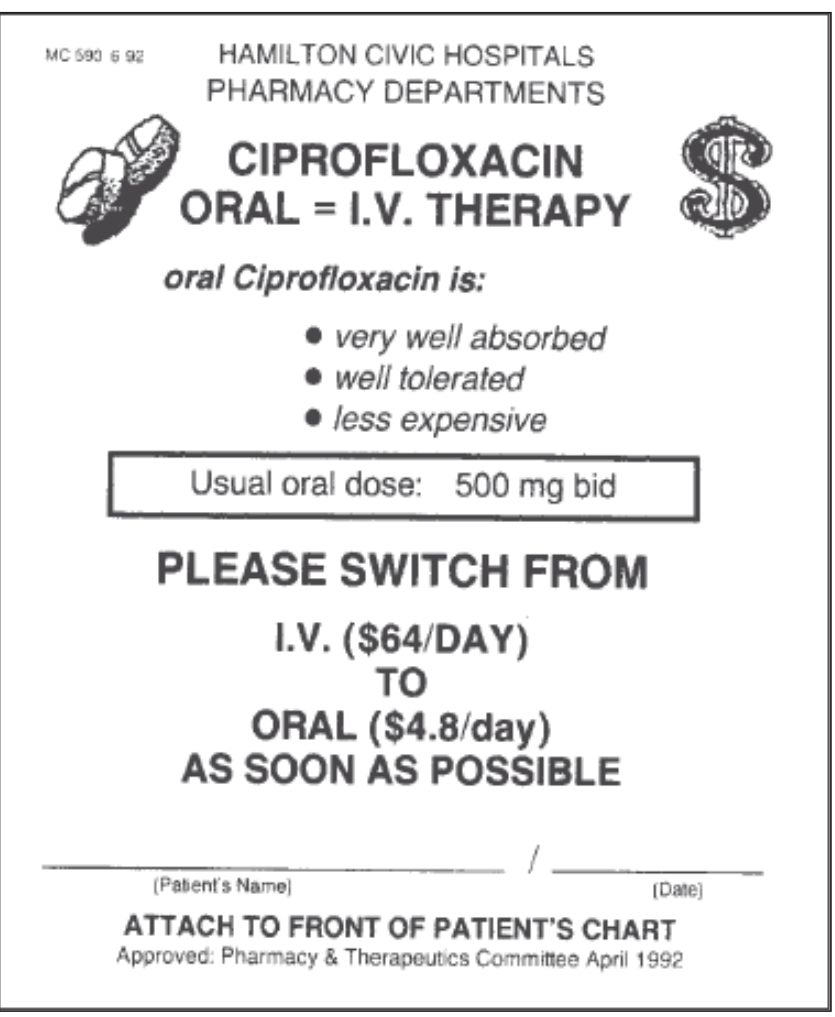

Figure 2) Sample of intravenous to oral reminder sticker

terchange notices, which were placed on the patient's medical record. The notices subsequently required countersignature by the physician as acknowledgement of the switch. The therapeutic interchanges are listed in Table 1 and an example of a therapeutic substitution notice is given in Figure 1.

Strategy 2 - antimicrobial restriction policy: The eight antimicrobials with the highest acquisition costs (ceftriaxone, ceftazidime, imipenem-cilastatin, vancomycin, tobramycin, amikacin, cefotetan and fluconazole) identified during the baseline data collection period were designated as restricted drugs. Use of any of these agents was permitted only if they were given for an approved indication. These indications were developed by the Infectious Diseases service and the pharmacy with approval by the Pharmacy and Therapeutics Committee. The indications were printed on the restricted antibiotic order form, which had to be completed and signed by the prescribing physician before release of the drug by the pharmacy. The drug could then be given for up to three days. These forms were reviewed daily by the pharmacy personnel and served as a quality assurance activity ensuring that antimicrobials were being prescribed appropriately. As with other antimicrobials, the three-day automatic stop order was also in effect to encourage reassessment of the need for further therapy with the restricted drug. It was also anticipated that, with additional clinical and laboratory data available after $72 \mathrm{~h}$, therapeutic options could be reevaluated. Physicians were then advised by pharmacy personnel if they failed to comply with accepted indications. Strategy 3 - parenteral to oral conversion: Specific antimicrobials available in parenteral and oral forms with appropriate

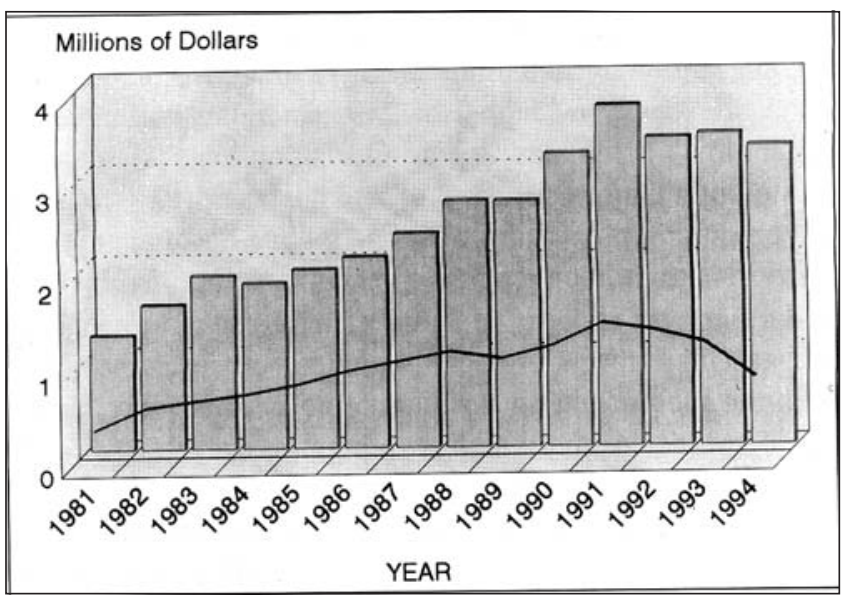

Figure 3) Antimicrobial expenditures as a percentage of the total drug acquisition costs from 1981 to 1994 . Bars represent total drug costs; the line indicates antimicrobial costs

TABLE 2

Annual drug pharmacy expenditures before and after program implementation

\begin{tabular}{lccc}
\hline Year & $\begin{array}{c}\text { Total drug } \\
\text { budget (\$) }\end{array}$ & $\begin{array}{c}\text { Antimicrobial } \\
\text { budget (\$) }\end{array}$ & $\begin{array}{c}\text { Percentage of } \\
\text { total budget }\end{array}$ \\
\hline 1991 & $3,697,017$ & $1,539,553$ & 41.6 \\
1992 & $3,344,750$ & $1,356,624$ & 40.6 \\
1993 & $3,382,655$ & $1,104,687$ & 32.6 \\
1994 & $3,252,305$ & 918,301 & 28.2 \\
\hline
\end{tabular}

pharmacokinetic properties and bioavailability profiles were selected. Oral administration of such agents could be considered as an alternative to the parenteral route if a patient was able to swallow and had a functioning gastrointestinal tract (15). Whenever one of these drugs was ordered for parenteral use, a yellow sticker giving cost and dosage details of the oral formulation was affixed to the chart as a reminder to the physician that oral treatment should be considered (Figure 2).

Antimicrobial usage patterns and acquisition costs for the baseline data period were compared with those for the twoyear period following implementation of the program. Cost minimization of the drug acquisition costs was analyzed. To minimize the effects of confounding variables such as bed closures and reduction in costs of certain drugs, the baseline and postintervention periods were compared in terms of the mean cost per dose of antimicrobials per patient day.

\section{RESULTS}

Antimicrobial expenditures as a percentage of the total drug acquisition costs for the Henderson General Hospital Pharmacy from 1981 to 1994 are given in Figure 3. With the introduction of new and more expensive drugs, total drug acquisition costs rose steadily, reaching a peak in 1991. In 1991, before implementation of the antimicrobial program, annual total acquisition costs were $\$ 3,697,017$, of which $41.6 \%$ was antimicrobial agents. Two years after implementation of the 


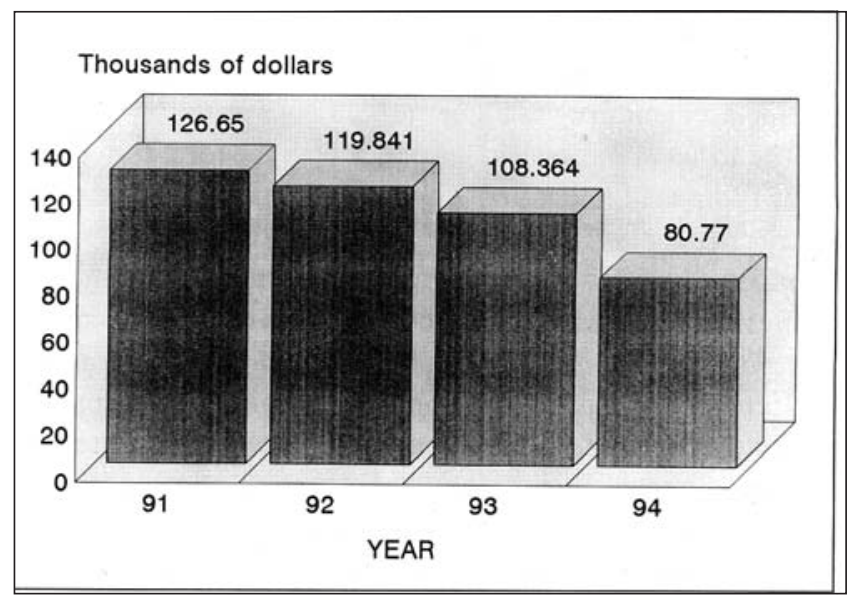

Figure 4) Average monthly antibiotic purchasing costs in the years 1991 to 1994

TABLE 3

Examples of annual costs and of cost savings after implementation of the program $(\$)$

\begin{tabular}{lccc}
\hline & $\begin{array}{c}\text { Before } \\
(\mathbf{1 9 9 1 )}\end{array}$ & $\begin{array}{c}\text { After } \\
\mathbf{( 1 9 9 4 )}\end{array}$ & $\begin{array}{c}\text { Cost } \\
\text { reduction (\$) }\end{array}$ \\
\hline $\begin{array}{l}\text { Therapeutic interchange } \\
\text { Cefotaxime/ } \\
\text { ceftriaxone }\end{array}$ & 75,767 & 36,142 & 39,625 \\
$\begin{array}{l}\text { Cefoxitin/cefotetan } \\
\text { Tobramycin/ }\end{array}$ & 48,981 & 28,333 & 20,648 \\
$\begin{array}{l}\text { gentamicin } \\
\text { Restricted IV antibiotics }\end{array}$ & 97,285 & 61,356 & 35,929 \\
$\begin{array}{l}\text { Ceftazidime } \\
\text { Vancomycin }\end{array}$ & 309,675 & 180,091 & 129,584 \\
$\begin{array}{l}\text { Imipenem } \\
\text { IV to oral }\end{array}$ & 218,337 & 212,481 & 5,856 \\
Metronidazole & 175,492 & 139,967 & 35,525 \\
Cotrimoxazole & 14,894 & 13,405 & 1,489 \\
\hline
\end{tabular}

IV Intravenous

program, the total drug budget had dropped by $14 \%$ to $\$ 3,252,305$ while the antimicrobial portion had been reduced by $13.4 \%$ to $28.2 \%$ of the total (Table 2 ). Thus, the antimicrobial budget fell by $\$ 621,252$, a decrease of $40 \%$.

Figure 4 demonstrates how the average monthly antimicrobial acquisition costs decreased during the study period from $\$ 126,650$ in 1991 to $\$ 80,770$ in 1994 . The mean monthly cost savings were $\$ 6,810$ in 1992 , $\$ 11,480$ in 1993 and $\$ 27,590$ in 1994.

The actual number of antimicrobial doses dispensed was also examined in relation to the number of patient days. There was a decline in the average number of patient days per month from 14,005 in 1991 to 11,669 in 1994 . However, while the mean number of antimicrobial doses dispensed per month fell from 9299 in 1991 to 8151 in 1994, the mean number of doses dispensed per patient day remained constant at 0.66. Calculation of the mean cost per dose per patient day revealed a drop from $\$ 11.88$ in 1991 to $\$ 10.16$ in 1994. Although it would

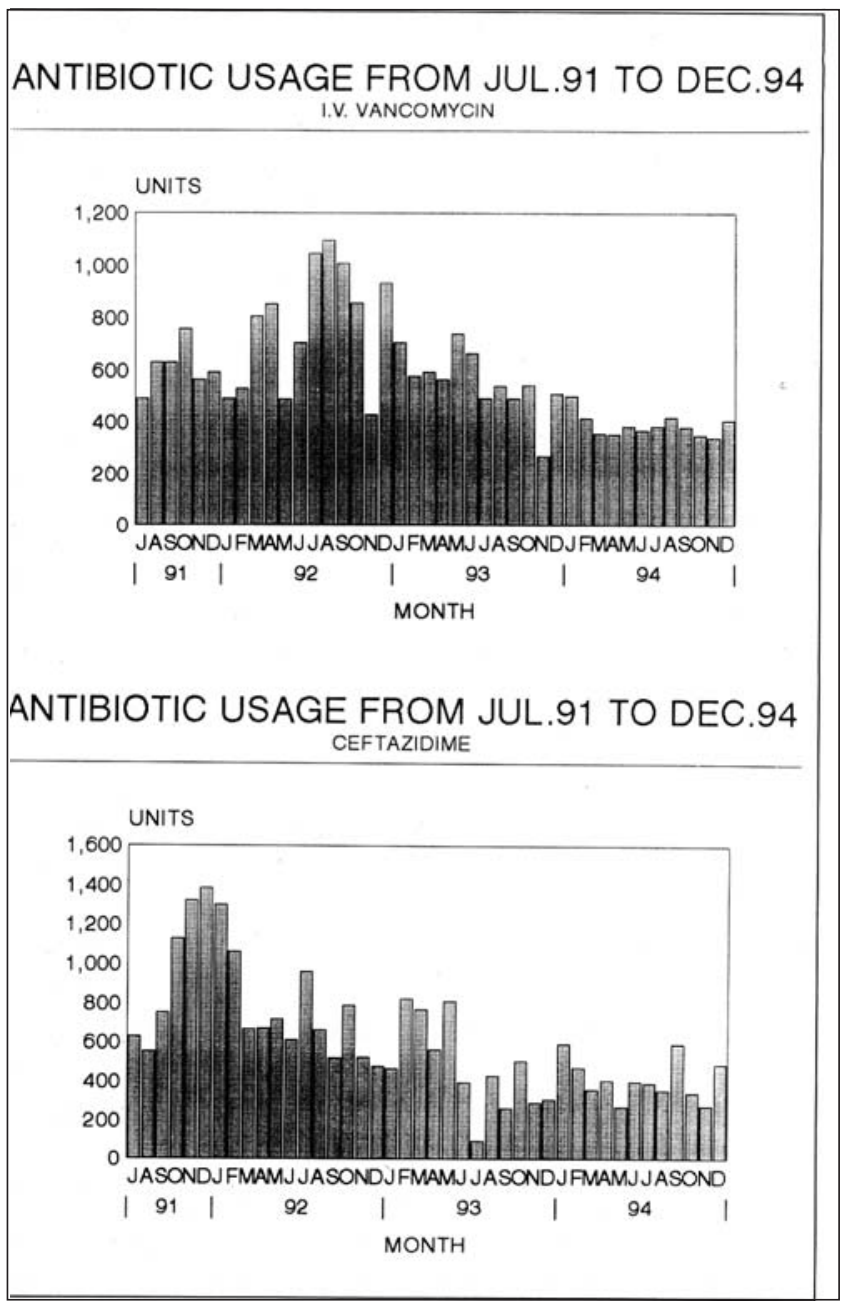

Figure 5) Monthly use patterns of intravenous (I.V.) vancomycin and ceftazidime before and after intervention in August 1992

have been desirable to assess the individual contribution of each of the strategies (automatic interchanges, restricted anti-microbials and parenteral to oral conversion) to the overall reduction in the mean cost per dose per day, it was impossible to do so. The initiation of the strategies simultaneously and the involvement of some antimicrobial agents in more than one strategy precluded this analysis.

Automatic therapeutic interchanges: Implementation of this part of the program was the least problematic. Examples of some of the cost savings realized are shown in Table 3. The most dramatic effect was an annual cost savings of $\$ 39,625$ due to the cefotaxime to ceftriaxone interchange, while a savings of $\$ 35,929$ was realized with the tobramycin to gentamicin interchange.

Restricted antimicrobial agents: The monthly use of all eight restricted antimicrobials either remained the same or declined after initiation of the program (Figure 5). The most significant annual cost savings were in the use of ceftazidime $(\$ 129,000)$, imipenem $(\$ 35,000)$ and vancomycin $(\$ 6,000)$.

Parenteral to oral conversion: Preliminary assessments (Table 3) showed disappointing cost reduction results with this strategy. This intervention, which was targeted at specific an- 
timicrobials rather than specific clinical syndromes, eg, osteomyelitis, did not have the anticipated impact on prescribing habits. It was found that for patients eligible for a possible switch from parenteral to oral therapy, the change was actually made in only $27 \%$ of cases. However, when a pharmacist was specifically assigned to monitor this aspect of the program, compliance improved dramatically to $75 \%$, resulting in an annual cost savings of $\$ 50,000$.

\section{DISCUSSION}

Historically, quality assurance in hospitals has always been of paramount importance. In recent years, however, cost containment has become a major concern for physicians and administrators alike. Ideally, programs that address both of these concerns are of greatest value and have the most significant impact. Our antimicrobial management program was instituted with two main objectives in mind: to increase the quality of antimicrobial prescribing and to control runaway costs of antimicrobial therapy.

A number of strategies have already been advocated to improve antimicrobial use, including approaches that are educative and persuasive, facilitative and restrictive (6). Unfortunately, educational programs alone do not seem to have the desired effect (16), whereas improved results have been reported with restrictive policies such as those that require written justification by the prescribing physician $(17,18)$. We felt that the best results would be obtained by combining education with facilitative and restrictive methods.

Our first step was to optimize the hospital formulary by limiting unnecessary drugs, implementing a three-day stop order and developing guidelines for antibiotic use. An appropriately designed formulary can lead to a reduction in cost of antimicrobials as well as more cost effective use of drugs by prescribing physicians (6). This, together with specific educational programs developed jointly by the infectious diseases and pharmacy departments, laid the groundwork for the introduction of our three-component antimicrobial management program: automatic therapeutic interchange, antimicrobial restriction, and parenteral to oral conversion or sequential antibiotic therapy (SAT).

Automatic therapeutic interchange usually involves the conversion by the pharmacy of one drug for another which has improved pharmacokinetic properties and/or lower acquisition costs. Examples of the former include conversion from cephalothin (half-life $0.5 \mathrm{~h}$ ) to cefazolin (half-life $1.8 \mathrm{~h}$ ) and cefoxitin (half-life $1 \mathrm{~h}$ ) to cefotetan (half-life $3.4 \mathrm{~h}$ ), while gentamicin is usually interchanged with tobramycin or amikacin for cost reasons $(19,20)$. The automatic interchange of ceftriaxone for cefotaxime not only resulted in a pharmacokinetic advantage but effected further cost savings when the customary ceftriaxone dose was reduced from $2 \mathrm{~g}$ every $24 \mathrm{~h}$ to $1 \mathrm{~g}$ every $24 \mathrm{~h}$ as part of our antimicrobial use program.

A United States study reported that administrative and preparation costs added US $\$ 7.00$ to the cost of each dose of intravenous antibiotics (21). In Australia, A \$4.55 to A \$10.58 is added to the cost of each intravenous dose (22). Other investigators have reported that, by simply replacing one intravenous drug with another that is given less frequently, considerable cost savings are realized even if the acquisition cost of the replacement drug is higher $(19,23)$.

The focus of our restrictive policy was the form that physicians completed indicating why they wished to use one of the restricted agents. The forms served a gatekeeper function and provided educational benefits as well, because each time that a physician wished to order one of these agents, he or she reviewed the approved indications listed on the form and indicated which of these was appropriate. The completed forms also provided a database for quality assurance review. Release of the restricted drug for three days allowed time for more data accrual relevant to the patient's condition and gave the physician ready but controlled access to all formulary items.

SAT refers to the practice of limiting the use of parenteral antibiotics to the early stages of infection and then changing to oral drugs for the remainder of treatment. This is not a new approach, and a number of papers published in the 1970s dealing with osteomyelitis and septic arthritis in children advocated using such methods (24-26). A literature search revealed 32 studies in support of SAT. Of these, 13 were randomized, controlled trials and 19 are nonrandomized studies (27). Both types of trials examined treatment of a variety of infections including sepsis, pneumonia, urinary tract infections and intra-abdominal infections. The evidence quite clearly supports the use of intravenous therapy followed by oral treatment in appropriate patients.

SAT is associated with economic benefits, patient benefits and benefits to the health care provider. At the Vancouver Hospital and Health Sciences Centre, an intravenous to oral conversion program has been in place for eight years and has resulted in savings of at least $\$ 30,000$ yearly, while a similar program at Hartford Hospital in Connecticut has projected an annual savings of US\$107,637 (28-30). Further savings are accrued by allowing out-of-hospital treatment since approximately one-half of costs associated with hospital therapy are due to simple board and care (31). One multicentre study involving 766 hospitalized patients showed that by using SAT an estimated 2266 hospital days were saved resulting in savings of $\$ 793,100$ (32). Patient benefits include increased comfort and mobility as well as a decreased risk of nosocomial infection. An earlier return to family and possibly to work further enhance quality of life. By lessening preparation and administration time, use of oral agents also decreases the amount of personnel time associated with drug delivery.

This antimicrobial use program has been very successful in that it has resulted in dramatic savings and may have shortened hospital stay in patients who were switched from parenteral to oral therapy. The reduction in monthly acquisition costs from $\$ 126,650$ to $\$ 80,770$ represents true cost savings. These savings are further verified by reduction in mean cost per dose per patient day from $\$ 11.88$ to $\$ 10.16$ and are independent of such variables as bed closures and market variations in drug acquisition costs. The program also served as a quality assurance activity to improve physician prescribing behaviour of antimicrobials. 


\section{REFERENCES}

1. McGowan JE. Antimicrobial resistance in hospital organisms and its relation to antibiotic use. Rev Infect Dis 1983;5:1033-48.

2. Parry MF. Epidemiology and mechanisms of antimicrobial resistance. Am J Infect Control 1989;17:286-94.

3. Bodey GP, Fainstein V, Garcia I, Rosenbaum B, Wong Y. Effect of broad-spectrum cephalosporins on the antimicrobial flora of recipients. J Infect Dis 1983;148:892-7.

4. McCue JD, Hansen C, Gal P. Hospital charges for antibiotics. Rev Infect Dis 1985;7:643-6.

5. Marr JJ, Moffet HL, Kunin CM. Guidelines for improving the use of antimicrobial agents in hospitals: a statement by the Infectious Diseases Society of America. J Infect Dis 1988;5:869-76.

6. Health Services and Promotion Branch, Department of National Health and Welfare Canada. Guidelines for antimicrobial utilization in health care facilities. Can J Infect Dis 1990;1:64-70.

7. Hess DA, Mahoney CD, Johnson PN, Corrao WM, Fisher AE. Integration of clinical and administrative strategies to reduce expenditures for antimicrobial agents. Am J Hosp Pharm 1990;47:585-91.

8. Zervos MJ, Kauffman CA, Therasse PM, Bergman AG, Mikesell TS, Schaberg DR. Nosocomial infection by gentamicin-resistant Streptococcus faecalis. An epidemiologic study. Ann Intern Med 1987;106:687-91.

9. Kunin CM. Evaluation of antibiotic usage. A comprehensive look at alternative approaches. Rev Infect Dis 1981;3:745-53.

10. Kunin CM, Tupasi T, Craig WA. Use of antibiotics: a brief exposition of the problem and some tentative solutions. Ann Intern Med 1973;79:555-60.

11. Simmons HE, Stolley PD. This is medical progress? Trends and consequences of antibiotic use in the United States. JAMA 1974;227:1023-8.

12. McGowan JE, Finland M. Usage of antibiotics in a general hospital: effect of requiring justification. J Infect Dis 1974;130:165-8.

13. Polk RE. The role of the infectious disease physician in monitoring antimicrobial use: a pharmacy perspective. Bull NY Acad Med 1987;63:612-6.

14. Zeman BT, Pike M, Samet C. The Antibiotic Utilization Committee. Hospitals 1984;48:73-6.

15. Quintiliani R, Nightingale CH, Crowe HM, Cooper BW, Bartlett $\mathrm{RC}$, Gousse G. Strategic antibiotic decision-making at the formulary level. Rev Infect Dis 1991;3(Suppl 9):S770-7.

16. Jones SR, Barks J, Bratton T. The effect of an educational program on hospital antibiotic use. Am J Med Sci $1977 ; 273: 79-85$.
17. Gleckman R, Gantz NM. Cost-effective antibiotic prescribing. Pharmacotherapy 1983;3:239-48.

18. McGowan JE Jr, Finland M. Infection and antibiotic usage at Boston City Hospital: changes in prevalence during the decade 1964-1973. J Infect Dis 1974;129:421-8.

19. Quintiliani R, Nightingale $\mathrm{CH}$. Antimicrobials and therapeutic decision making: an historical perspective. Pharmacotherapy 1991;11(Pt 2):6S-13S.

20. Quintiliani R, Cooper BW, Briceland LL, Nightingale $\mathrm{CH}$. Economic impact of streamlining antibiotic administration. Am J Med 1987;82(Suppl 4A):391-4.

21. Rush DR. Antimicrobial formulary management: meeting the challenge in the community hospital. Pharmacotherapy 1991;11(Pt 2):19S-26S.

22. Plumridge RJ. Cost comparison of intravenous antibiotic administration. Med J Aust 1990;153:516-8.

23. Wright DB. Antimicrobial formulary management: a case study in a teaching hospital. Pharmacotherapy 1991;11(Pt 2):27S-31S.

24. Feigin RD, Pickering LK, Anderson D, Keeney RE, Shackleford PG. Clindamycin treatment of osteomyelitis and septic arthritis in children. Pediatrics 1975;55:213-23.

25. Tetzlaff TR, McCracken GH, Nelson JD. Oral antibiotic therapy for skeletal infections of children. II. Therapy of osteomyelitis and suppurative arthritis. J Pediatr 1978;92:485-90.

26. Bryson YJ, Connor JD, LeClerc M, Giammona ST. High-dose dicloxacillin treatment of acute staphylococcal osteomyelitis in children. J Pediatr 1979;94:673-5.

27. Mandell LA, Bergeron MG, Gribble MJ, et al. Sequential antibiotic therapy: effective cost management and patient care. Can J Infect Dis 1995;6:306-15.

28. Frighetto L, Nickoloff D, Martinusen SM, Mamdani FS, Jewesson PJ. Intravenous-to-oral stepdown program: four years of experience in a large teaching hospital. Ann Pharmacother 1992;26:1447-51.

29. Jewesson P. Cost-effectiveness and value of an IV switch. Pharmacoeconomics 1994;5(Suppl 2):20-6.

30. Briceland LL, Nightingale CH, Quintiliani R, Cooper BW, Smith KS. Antibiotic streamlining from combination therapy to monotherapy utilizing an interdisciplinary approach. Arch Intern Med 1988;148:2019-22.

31. Chrysanthopoulos CJ, Skoutelis AT, Bassaris HP. Shortened hospital stay with sequential intravenous oral ciprofloxacin. Drugs 1993;45(Suppl 3):464.

32. Grasela TH Jr, Paladino JA, Schentag JJ, et al. Clinical and economic impact of oral ciprofloxacin as follow-up to parenteral antibiotics. Ann Pharmacother 1991;25:857-62. 


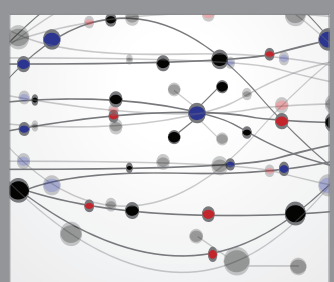

The Scientific World Journal
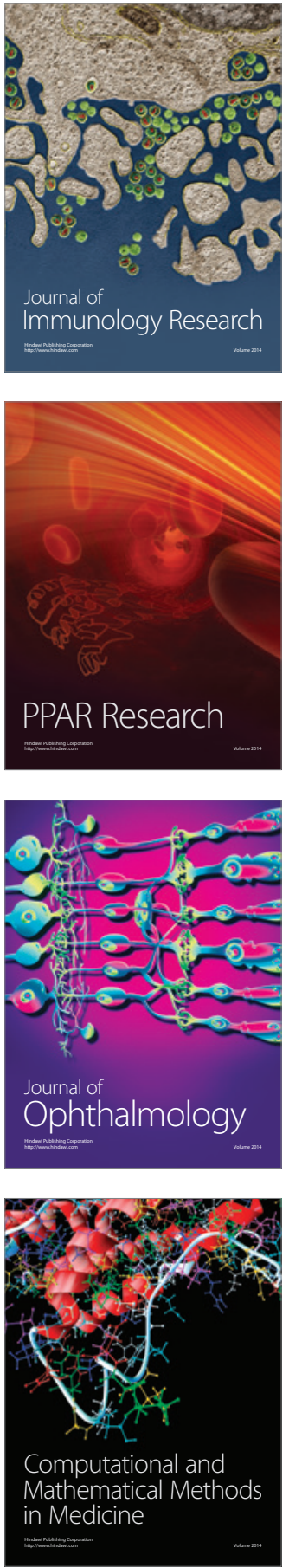

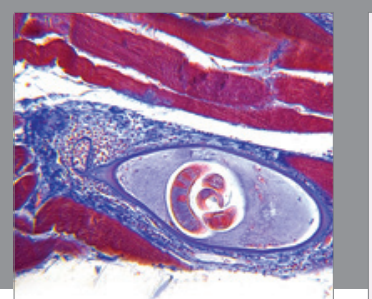

Gastroenterology Research and Practice

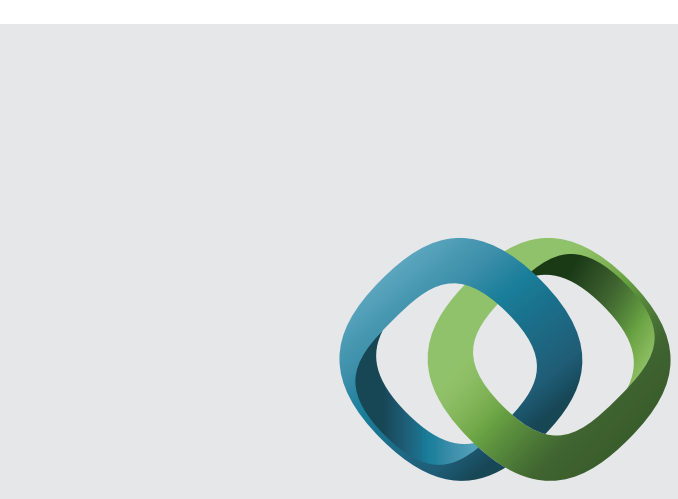

\section{Hindawi}

Submit your manuscripts at

http://www.hindawi.com
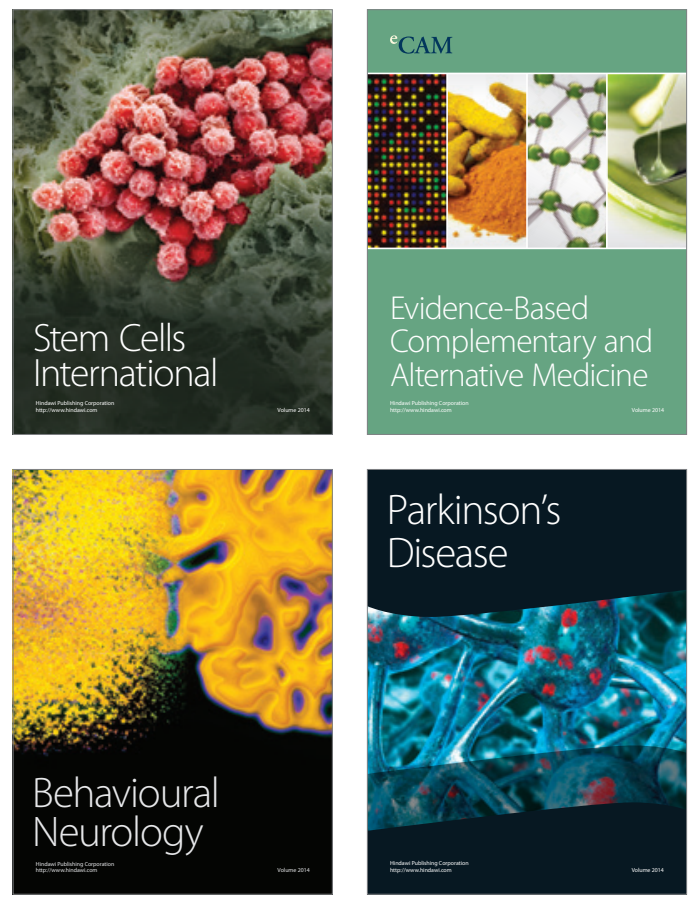
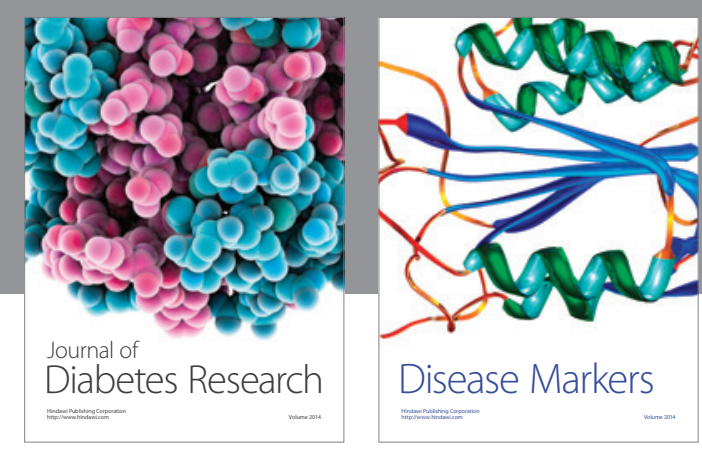

Disease Markers
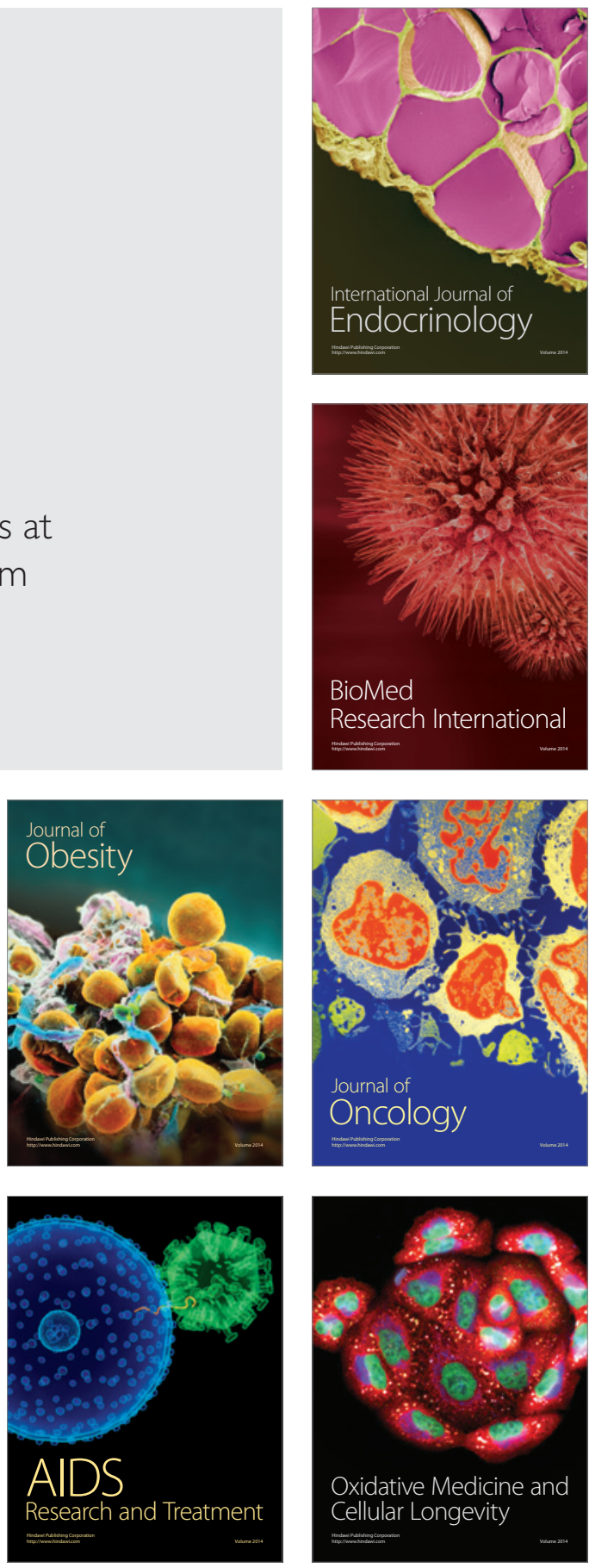